\title{
Health geography: supporting public health policy and planning
}

\section{Trevor J. B. Dummer PhD}

$\mathrm{G}$ eography and health are intrinsically linked. Where we are born, live, study and work directly influences our health experiences: the air we breathe, the food we eat, the viruses we are exposed to and the health services we can access. The social, built and natural environments affect our health and well-being in ways that are directly relevant to health policy. Spatial location (the geographic context of places and the connectedness between places) plays a major role in shaping environmental risks as well as many other health effects. ${ }^{1}$ For example, locating health care facilities, targeting public health strategies or monitoring disease outbreaks all have a geographic context.

\section{What is health geography?}

Health geography is a subdiscipline of human geography, which deals with the interaction between people and the environment. Health geography views health from a holistic perspective encompassing society and space, and it conceptualizes the role of place, location and geography in health, well-being and disease. ${ }^{2,3}$ Although health geography is closely aligned with epidemiology, its distinct primary emphasis is on spatial relations and patterns. Whereas epidemiology is predicated on the biomedical model and focuses on the biology of disease, health geography seeks to explore the social, cultural and political contexts for health within a framework of spatial organization. Traditionally, research in health geography spans 2 distinct avenues: the patterns, causes and spread of disease, and the planning and provision of health services. Research in these interlinked areas supports policy development. For example, disease epidemiology is in part related to the geography of health service provision. ${ }^{4}$

\section{Why geography is important for public health policy}

Informed decision-making leads to the development of effective public health policy based on evidence. We need to understand disease risk factors and how risks such as genetics, lifestyle, environment and occupation interact with the social, built and natural environments. ${ }^{5}$ Understanding geography, including the arrangement of health services and the location and nature of environmental exposures, is crucial in assessing the interrelations inherent in many health-related risk exposures.

Many core geographic research themes, including health in- equalities and polarization, scale, globalization and urbanization, ${ }^{6}$ are directly related to public health. The scope and breadth of health geography research is diverse and wide-ranging, and examples of some common research areas relevant to public health policy are provided in Table I. These research areas are not mutually exclusive and some of the examples span multiple areas and themes. In the paragraphs that follow, we discuss these research themes in more detail to provide insight into the role of health geography in public health.

\section{Spatial scale, globalization and urbanization}

Concern with scales of organization is crucial to health service provision and public health implementation. For instance, global issues, such as environmental change, demographic transition and the internationalization of health service organization, all have geographic contexts that directly influence health policy. ${ }^{6}$ Global patterns in infectious diseases, including the spread of HIV/AIDS, avian influenza and severe acute respiratory syndrome, are linked to migration, population movement and disease diffusion. These processes, in turn, are affected by regional and local contexts such as socio-economic and labour-market conditions.

The growth of cities and the changing nature of the built environment has historically had and continues to have a profound effect on health and well-being. For example, the worldwide obesity epidemic is connected to factors that influence global warming (e.g., changing transportation patterns that influence the emission of greenhouse gases) and to factors that influence the structure of local built environments and socio-cultural shifts affecting physical activity, food availability and consumption. In this context, health policy issues should inform local planning policy, transportation, food policy and marketing in a geographically sensitive manner. Figure I provides an example of how the built environment can influence children's food choices and population obesity.

\section{Social and spatial inequalities in health}

Concerns about social and spatial polarization - especially with socio-economic inequalities, inequities and poverty -

Dr. Dummer is with the IWK Health Centre and the Canadian Centre for Vaccinology, Halifax, NS

Une version française de cette article est disponible à l'adresse www.cmaj.ca/cgi/content/full/I78/9/II77/DCI 
have prompted research that explores the determinants and consequences of health variations, including issues related to poverty, health care access and public health. The identification of persistent inequalities in health between rich and poor people and between rich and poor communities has provided evidence that can support policies to address the underlying causes of health problems. ${ }^{17,18,21}$ With respect to global, national and regional processes, the local contexts of places and peoples' everyday lives are crucial and evolving considerations for health policy development.

\section{Approaches to geographic research}

Geographic research in health is often dichotomized between quantitative and qualitative methodologies, with quantitative studies closely aligned with epidemiology and qualitative studies aligned with medical sociology and social sciences. Although differences in approach are important for the assessment of complex problems, these methodologies share a common theme: the role of place and space in health. For example, a quantitative study of an outbreak of an infectious disease such as mumps might focus on spatial modelling of disease diffusion, whereas a qualitative investigation might focus on socio-cultural influences on vaccination uptake within communities, the characteristics of which have been defined within an epidemiology-health geography framework. Often, health geographers will combine quantitative and qualitative methods in complimentary mixed-methods approaches. Geographers contribute to methodologic developments that are useful in health research, including multi-level statistical models, cluster analysis and geographically weighted regression analysis. ${ }^{22}$

Geographic information systems are a valuable addition to the health geographer's toolkit. A geographic information system is a computerized system for collecting, storing, representing and manipulating spatial data, and such systems are increasingly being used to interrogate and analyze healthrelated information to investigate health outcomes and health care provision. ${ }^{23}$ Geographic information systems support public health in diverse ways, including mapping, monitoring and modelling infectious and chronic diseases, disease surveillance and outbreak detection, emergency preparedness, and targeting interventions and health promotion initiatives. Recent innovative research based on geographic information systems can shed new light on the impact of the built environment on physical activity levels, diet and the problem of increasing obesity. ${ }^{24}$

Although health geographers often use traditional epidemiologic approaches, for example in both study design and statistical analysis, the discipline also makes use of distinct analytical tools, including geographic information system methods for integrating, mapping and analyzing data and spatial analysis statistical techniques, including clustering and spatial interpolation methods.

\section{Health and place: a caution and recognition}

When using geographic methods, it is important to be aware of the potential risks. Policy derived from geographic research can fall victim to ecological fallacy, in which incorrect assumptions are made about people based on aggregated data about their communities. ${ }^{22}$ This may result in the misapplication of policy targeting specific groups of people or places. The modifiable areal unit problem, which is a potential source of error, arises when an identified geographic pattern is partly a consequence of the size and shape of the areal

Table 1: Examples of health geography research relevant to public health policy

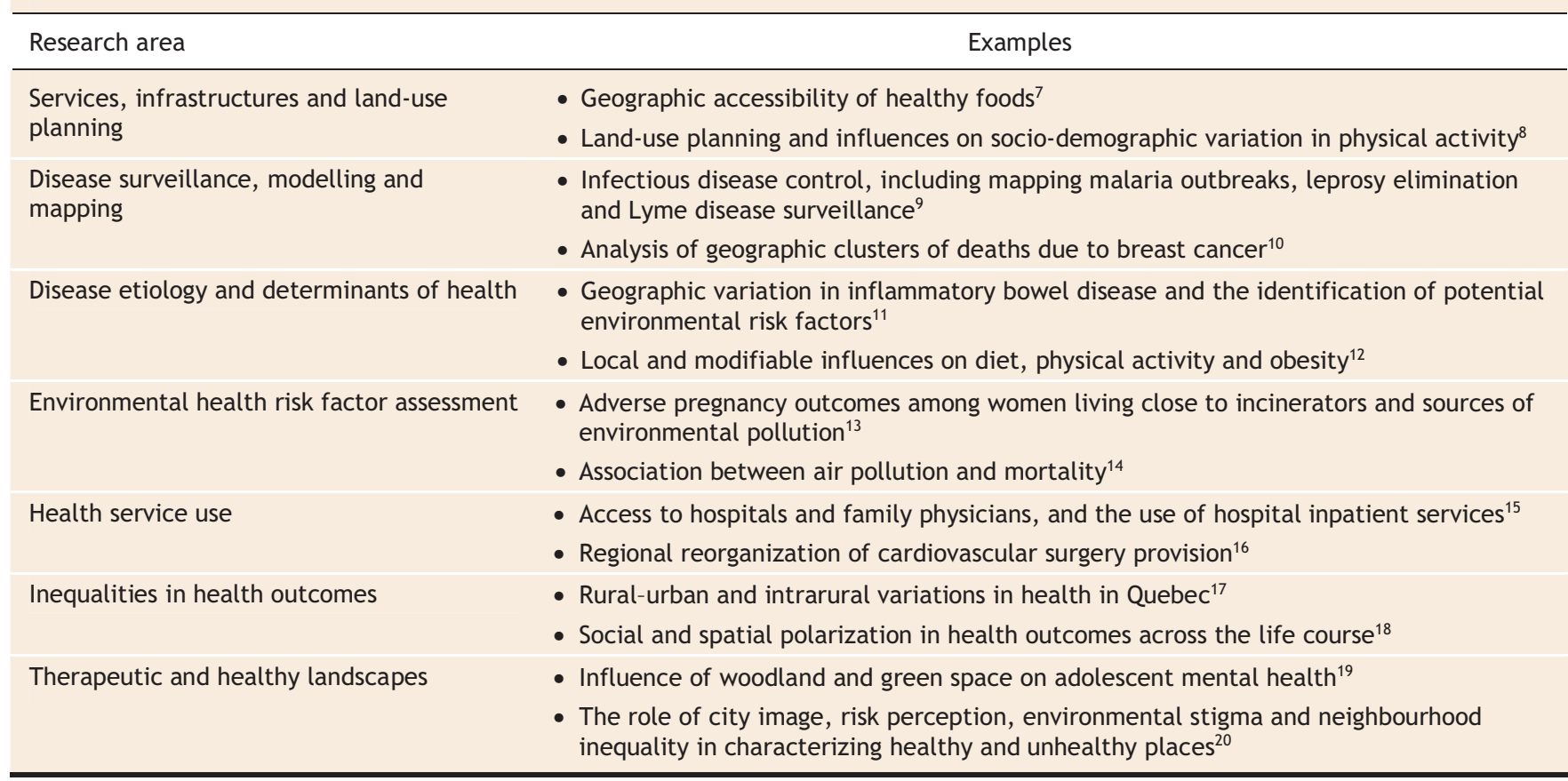


units used in the study. ${ }^{22}$ Although maps are important tools for visualizing health information and supporting policy decisions, the choice of areal units and the aggregation and categorization of data must be considered when interpreting the results.

Limitations aside, place and geographic context are recognized as important influences on health. ${ }^{25,26}$ Although ecologic fallacy has been used to dismiss ecologic (aggregate) studies as unreliable and blunt instruments useful only for showing broad patterns, it is now recognized that many risk factors do operate at the population or community level. ${ }^{25}$ These risks may modify effects, such as interaction between genes and chemical pollutants, or directly influence health. Dismissing ecologic studies neglects the geographic context within which health outcomes occur. ${ }^{25}$ Advances in multilevel modelling, geographic information systems and spatial analysis further supports research investigating the relative influence of individual- and community-level health risks within a unified framework.

Current developments in health geography include a stronger focus on health inequalities and the impact of spatial and social marginalization on health, and more explicit exploration of the nature of health change. ${ }^{6}$ The latter acknowledges that spatial relations are dynamic and that health variation can be a consequence of individual mobility, and population movement and migration. Geographic information systems, which support the analysis of dynamic spatial data, ${ }^{27}$ are being more closely aligned with global positioning systems to monitor the movement of people in real time to contextualize the interrelations between the physical and built environments, people's daily routines and their health. However, there are both technical (e.g., the development of appropriate computer software and hardware to capture

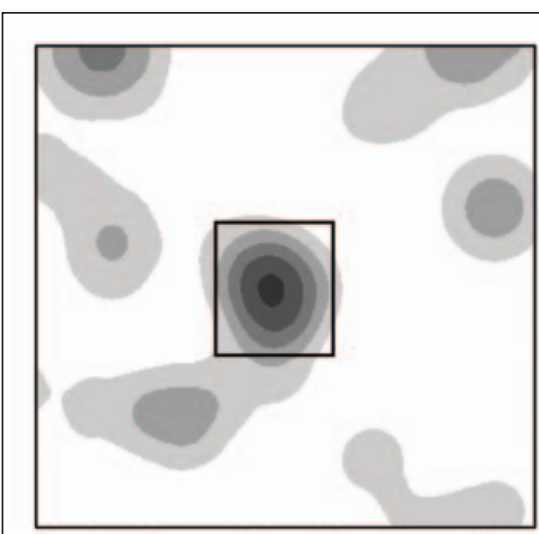

Map A: Area of 'good' eating habits

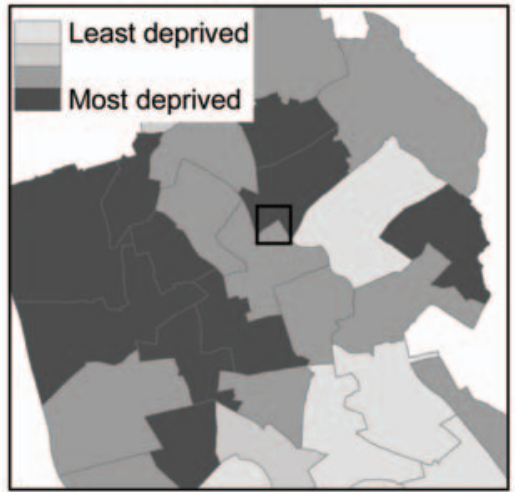

Map B: Census ward deprivation

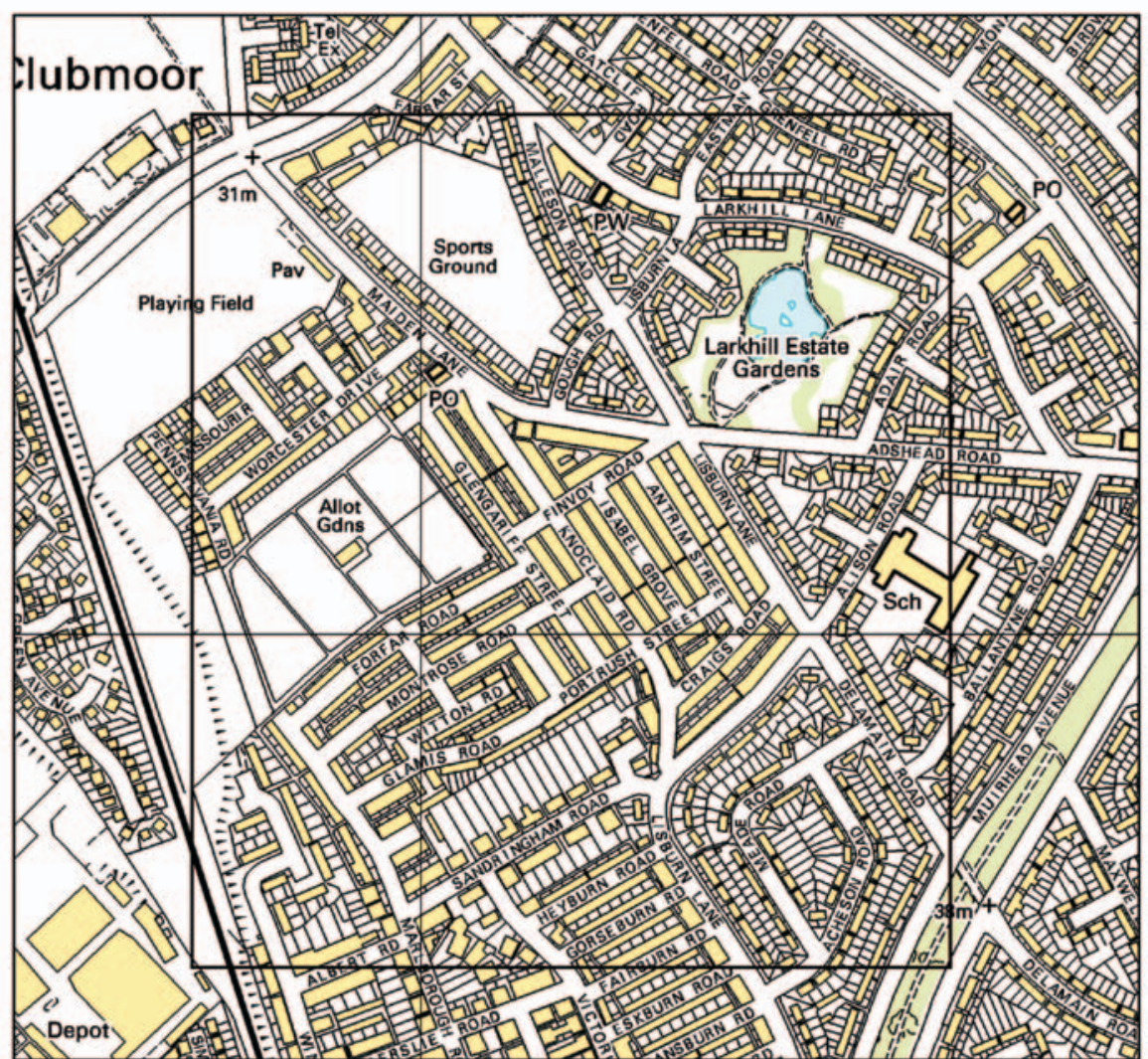

Map C: Local built environment

Crown Copyright / Database right 2007, An Ordnance Survey / Edina Digimap Service

Figure 1: Exploratory spatial analysis of children's eating habits in Liverpool, United Kingdom. Data on individual children's food choices in Liverpool were mapped to identify areas of good eating habits (darker shaded areas in Map A). A small area of good eating habits (boxed area in Map A) is located in a community that crosses 2 census wards (Map B). One of these wards has a very high level of socio-economic deprivation and poverty (Map B). However, Map C shows that, despite the high level of deprivation, the local built environment contains many open spaces, parks, recreation facilities and allotment gardens for growing fruit and vegetables, and these factors are potentially associated with children making better diet choices. The use of a geographic approach for analyzing, mapping and integrating different data sets allows data to be explored in a novel way. Although this is an exploratory method, it provides some hypotheses, such as the role of the built environment in influencing food choices, that can be analytically tested and that can provide suggestions for policies that might help tackle obesity problems. Used with permission from EDINA/Ordnance Survey. (c) Crown Copyright/database right 2007. An Ordnance Survey/EDINA supplied service. 
and analyze these data) and ethical (e.g., access to appropriate data, the privacy and confidentiality of personal information) challenges in improving these systems. ${ }^{27}$

\section{Conclusion}

Health geography recognizes the importance of context, setting and spatial scale - from global to local - in determining health outcomes. The issues facing health and health care are complex and an integrative, multidisciplinary approach is crucial to ensure that research provides relevant, high-quality evidence to inform health policy. Partnerships among health specialists, geographers and others can help sustain innovative approaches to solving complex problems and ultimately reduce inequity.

This article has been peer reviewed.

Competing interests: None declared.

Acknowledgements: I thank my colleagues Allan Hackett, Lynne Boddy, John Boothby, Brian Johnson and Gareth Stratton, Liverpool John Moores University, United Kingdom, for collaborating on the research from which the maps in Figure I were derived as part of the wider Liverpool SportsLinx project. I also thank Louise Parker for her comments on an earlier draft of the manuscript.

\section{REFERENCES}

I. Tunstall HVZ, Shaw M, Dorling D. Places and health. J Epidemiol Comm Health 2004;58:6-Io.

2. Meade M, Earickson R. Medical geography. New York: Guilford Press; 2000

3. Mayer JD. Geography, ecology and emerging infectious diseases. Soc Sci Med 2000;50:937-52.

4. Jones K, Moon G. Health, disease and society: an introduction to medical geography. London: Routledge and Kegan Paul; 1987.

5. Dahlgren G, Whitehead M. Policies and strategies to promote social equity in health. Stockholm: Institute for Future Studies; I99I.

6. Asthana S, Curtis S, Duncan C, et al. Themes in British health geography at the end of the century: a review of published research $1998-2000$. Soc Sci Med 2002;55:167-73

7. Burns CM, Inglis AD. Measuring food access in Melbourne: access to healthy and fast foods by car, bus and foot in an urban municipality in Melbourne. Health Place 2007; $13: 877-85$

8. Aytur SA, Rodriguez DA, Evenson KR, et al. The sociodemographics of land use planning: relationships to physical activity, accessibility, and equity. Health Place. DOI Io.Ior6/j.healthplace.2007.08.004. Epub 2007 Aug ir ahead of print.

9. Boulos MN, Roudsari AV, Carson ER. Health geomatics: an enabling suite of technologies in health and healthcare. J Biomed Inform 2001;34:195-219.

Io. Kulldorff M, Feuer EJ, Miller BA, et al. Breast cancer in north-eastern United States: a geographical analysis. Am JEpidemiol 1997;146:I6I-70.

II. Green C, Elliott L, Beaudoin C, et al. Population-based ecologic study of inflammatory bowel disease: searching for etiologic clues. Am J Epidemiol 2006;164:615-23.

I2. Stafford M, Cummins S, Ellaway A, et al. Pathways to obesity: identifying local, modifiable determinants of physical activity and diet. Soc Sci Med. DOI Io.ror6 /j.socscimed.2007.05.042. Epub 2007 Jul 20 ahead of print.

I3. Dummer TJB, Dickinson HO, Parker L. Adverse pregnancy outcomes around incinerators and crematoriums in Cumbria, north west England, 1956-93. J Epidemiol Community Health 2003;57:456-6r.

I4. Elliott P. Shaddick G, Wakefield JC, et al. Long term associations of outdoor air pollution with mortality in Great Britain. Thorax 2007;62:1088-94.

15. Haynes R, Bentham G, Lovett A, et al. Effects of distances to hospital and GP surgery on hospital inpatient episodes, controlling for needs and provision. Soc Sci Med I999;49:425-33.

I6. Quesnel-Barbet A, Nuttens MC, Aublet-Cuvellier B, et al. Modelling a regional reorganization of cardiovascular surgery provision. Health Place 2005;II:283-92.

I7. Pampalon R, Martinez J, Hamel D. Does living in rural areas make a difference for health in Québec? Health Place 2006;12:42I-35.

I8. Shaw M, Dorling D, Gordon D, et al. Putting time, person and place together: the temporal, social and spatial accumulation of health inequality. Crit Public Health 200I;II:289-304.

I9. Milligan C, Bingley A. Restorative places or scary spaces? The impact of woodland on the mental well-being of young adults. Health Place 2007;13:799-8II.

20. Wakefield S, McMullan C. Healing in places of decline: (re)imagining everyday landscapes in Hamilton, Ontario. Health Place 2005;11:299-312.

2I. Marmot M. Social determinants of health inequalities. Lancet 2005;365:1099-I04.

22. Fotheringham AS, Brunsdon C, Charlton M. Quantitative geography: perspectives on spatial data analysis. London: Sage; 2000.

23. Pearce J. Incorporating geographies of health into public policy debates: The GeoHealth Laboratory. NZ Geog 2007;3:149-53

24. Frank LD, Andresen MA, Schmid TL. Obesity relationships with community design, physical activity, and time spent in cars. Am J Prev Med 2004;27:87-96.

25. Pearce N. The ecological fallacy strikes back. J Epidemiol Community Health 2000;54:326-7.

26. Cummins S, Curtis S, Diez-Roux AV, et al. Understanding and representing 'place' in health research: a relational approach. Soc Sci Med 2007;65:1825-38.

27. Boothby J, Dummer TJB. Facilitating mobility? The role of GIS. Geography 2003;88:300-II.

Correspondence to: Dr. Trevor Dummer, IWK Health Centre, Goldbloom RCC Pavilion, 5850/5980 University Ave., PO Box 9700, Halifax NS B3K 6R8; trevor.dummer@iwk.nshealth.ca

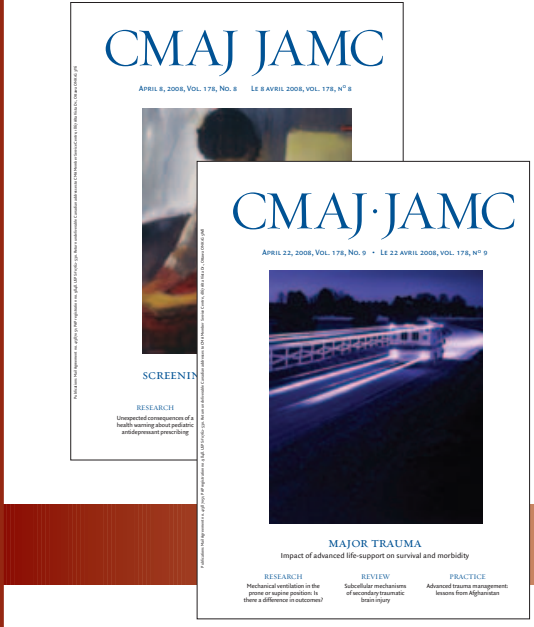

\section{Online manuscript submission and peer review available for $C M A J$}

